\title{
A tradução de suculentos jogos de palavras, sem perder o sabor
}

\section{Translating juicy wordplays without losing their flavor}

Stella E. O. Tagnin

Universidade de São Paulo (USP), São Paulo, SP.

seotagni@usp.br

Resumo: Este artigo discute algumas questões levantadas durante a tradução para o português de títulos de receitas de um livro britânico de sucos para crianças, com especial atenção para as diferenças culturais envolvidas nesse tipo de tradução. A maioria dos títulos baseia-se em jogos de palavras ou algum tipo de metáfora - imagética ou conceitual - que se espera sejam mantidos na tradução, de modo a preservar o apelo que esses títulos têm para o público infantil, pois, em geral fazem referência ao universo da criança. Linguisticamente, os títulos envolvem colocações, rimas e aliterações. Culturalmente, há referências a jogos infantis, canções e heróis que, na maioria das vezes, não são as mesmas na nossa cultura. Alguns títulos são baseados na cor do suco (Red devil), outros no ingrediente principal (Crazy kiwi), outros ainda no efeito desejado (Battery charge). A tradução de jogos de palavras exige certo grau de elaboração semântica, especialmente quando várias camadas de significado estão envolvidas. Serão apresentados vários exemplos que envolvem diferenças culturais entre a Inglaterra e o Brasil, assim como as soluções a que se chegou, sempre na tentativa de manter o jogo de palavras dentro do universo infantil.

Palavras-chave: jogos de palavras; tradução; cultura; títulos; convencionalidade.

Abstract: This paper discusses various issues raised in the Portuguese translation of titles of juice recipes for children from a British recipe book, paying special attention to cultural differences involved in this type of 
translation. Most titles involve either wordplay or some kind of metaphor image or conceptual - which was expected to be retained in the translation so as to preserve the appeal these titles have for children as they usually make reference to the child's universe. Linguistically, titles involve collocations as well as rhymes and alliteration. Culturally, references are made to children's games, songs and heroes which, more often than not, are different across cultures. Some titles are based on the color of the juice (Red devil), some on the main ingredient (Crazy kiwi), some on the desired effect (Battery charge). When these convey prototypical meanings, translation can be quite straightforward. Wordplay, on the other hand, demands a certain degree of semantic elaboration, especially when various layers of meaning are involved. We will present various examples that involve cultural differences between Britain and Brazil, as well as the solutions we arrived at always attempting to somehow reproduce the wordplay in the child's universe.

Keywords: wordplay; translation; culture; titles; conventionality.

Recebido em: 30 de julho de 2015. Aprovado em: 2 de setembro de 2015.

\section{Introdução}

Traduzir, em si, como todos sabem, não é uma tarefa trivial. Quando a tradução envolve jogos de palavras, então, a dificuldade é muito maior, principalmente porque nem sempre - ou quase nunca- há uma equivalência linguística entre as duas línguas que permita reproduzir o efeito desejado na língua de chegada. A situação pode se tornar ainda mais complicada quando entram em jogo aspectos culturais típicos de uma língua e inexistentes na outra. Outro agravante ainda poderia ser representado pelo público-alvo, isto é, quando se trata de um público específico.

Foram esses os problemas enfrentados na tradução de um livro britânico de receitas de sucos saudáveis para crianças intitulado Juices \& Smoothies for Kids (CROSS, 2007a), que recebeu o título Sucos e Vitaminas para Crianças em português (CROSS, 2007b). 


\section{0 livro}

O livro Juices \& Smoothies for Kids contém mais de sessenta receitas, cujos títulos pretendem ser apelativos ao público infantil, empregando muitas vezes jogos de palavras, certamente para incentivar as crianças a consumir o alimento. Cada receita é introduzida por um pequeno texto, descrevendo suas características e funções. Por exemplo, já na tradução para o português:

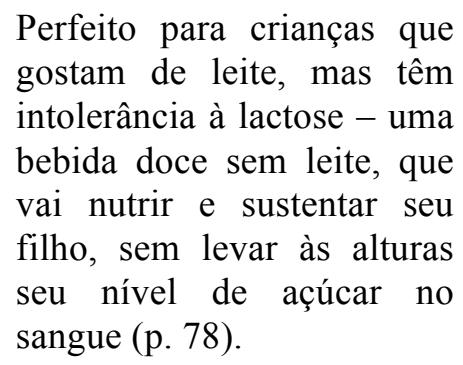

Do total das receitas, selecionamos os títulos que apresentaram maior dificuldade de tradução. Para facilitar a discussão, esses foram agrupados conforme o problema envolvido, mas devemos lembrar que nenhuma categorização é absolutamente precisa.

\section{Revisão da literatura}

Quando se pensa em tradução de jogos de palavras, imediatamente pensa-se na tradução de humor e, mais especificamente, na de piadas. De fato, boa parte da literatura foca nesse aspecto (NIEDZIELSKI, 1991; SCHMITZ, 1996; ZABALBEASCOA, 1996, BREZOLIN, 1997; ROSAS, 2002; ATTARDO, 2002, entre muitos outros). Há, porém, vasta literatura sobre a tradução de jogos de palavras em geral, a exemplo de Tagnin (2005) e Delabastita (1997) que reuniu vários ensaios sobre o tema. Outros artigos, alguns abordando filmes ou séries televisivas, são Delabastita (1996), Stewart (2000) e Asimakoulas (2004). Vários trabalhos de conclusão de curso, inclusive de cursos de 
graduação e especialização, também têm se dedicado ao tema, dentre eles, Cunha (2004), Silva (2006), Brunet (2014) e Silva (2015).

A tônica dessa produção é que a tradução, nesses casos, deve privilegiar o 'efeito' em detrimento da forma, estratégia que vai ao encontro dos preceitos da teoria funcionalista da tradução (Reiss \& Vermeer, 1996) (SCHÄFFNER, 2009). Um dos preceitos dessa teoria é que a tradução deve ser moldada pelo objetivo (escopo na terminologia de Vermeer) a que se destina, levando em conta principalmente as diferenças entre a cultura do texto de partida e a do texto de chegada. Certamente, de um modo geral, foi o que orientou a tradução dos títulos em questão, já que se pretendia que esses, em português, despertassem nas crianças brasileiras o mesmo efeito lúdico que, supõe-se, a autora esperava que tivesse nas crianças inglesas.

Outro preceito que regeu as traduções foi o da 'naturalidade' (TAGNIN, 2013) - os títulos teriam de soar 'naturais' para o públicoalvo. Por naturalidade entendemos a forma usual de se expressar, a mais provável de ocorrer em determinado contexto. Na tentativa de recriar um jogo de palavras, não nos bastava tentar uma tradução que se aproximasse do jogo original se não representasse um 'modo de dizer' consagrado.

Além disso, conforme alerta Philip (2009), há uma nítida diferença entre o significado de uma palavra em seu contexto convencional de uso e seu sentido num uso não convencional da língua, ou seja, quando é usada de forma criativa. Isso deve ser reconhecido e levado em conta na tradução. Em outras palavras, é preciso primeiro reconhecer que a palavra ou expressão está sendo usada de forma criativa e então tentar recriar esse efeito na tradução. Vejamos, então, como foi esse processo na tradução dos títulos desse livro de sucos para crianças.

\section{Os títulos}

A autora empregou vários recursos para nomear os sucos sugeridos. Em termos lexicais, empregou colocações em novos contextos; como recursos prosódicos, fez uso de rimas e aliterações; no âmbito cultural, lançou mão de nomes de jogos, canções e personagens 
infantis. No entanto, os títulos eram, em sua maioria, motivados; por exemplo, Go green e Yellow submarine refletiam a cor do suco; Crazy kiwi e Apple aid incluíam o ingrediente principal; Sweet and sour revelava o sabor. Já outros tinham certo viés metafórico, aludindo ao efeito desejado: Energy bubble e Battery charge. Claramente metafórico era Kick start, termo que se refere a dar partida numa moto.

$\mathrm{O}$ objetivo das traduções era ater-se, o tanto quanto possível, à 'forma' original, desde que mantivesse, como já dissemos, o efeito 'apelativo'. Em alguns poucos casos, uma tradução literal permitia isso:

\begin{tabular}{|l|l|}
\hline Apricot cloud & Nuvem de damasco \\
Battery charge & Carga na bateria \\
Crazy kiwi & Kiwi maluco \\
Doctor, doctor & Doutor, doutor \\
Hug in a glass & Abraço no copo \\
\hline
\end{tabular}

No entanto, vários outros demandaram um conhecimento maior da convencionalidade da língua inglesa - o 'reconhecimento' a que se refere Philip (2009) - para evitar uma tradução literal que não soasse natural em nossa língua.

\subsection{Títulos com colocações}

As colocações representam uma das categorias convencionais bastante usada em títulos e, muitas vezes, manipulada para efeitos retóricos ou humorísticos. Para reconhecer essa manipulação é necessário estar familiarizado com a colocação. Tomando emprestada uma noção de Fillmore (1979), poderíamos chamar de "tradutor ingênuo" aquele que só entende a língua literalmente e assim a traduz. Vejamos alguns casos de colocações: Sky high apresenta 18.500.000 resultados no Google, significa 'de alto nível', e é bastante usada como nome próprio: Sky High Car Audio (uma loja), Sky High Wilderness Ranch (local de aventuras), Sky High Sports (academia). Foi também o título de um filme de 2005, cujo título em português era Sky High -

\footnotetext{
${ }^{1}$ Acesso em: 20 jul. 2015.
} 
Escola de Heróis, ou seja, manteve-se o original, acrescido de um texto que alude ao significado de 'alto nível' da colocação, na medida que inclui 'heróis', personagens de 'alto valor', de grandes conquistas.

Um tradutor ingênuo a traduziria como 'céu alto' ou 'alto céu', combinação inexistente em português. Cabe, então, buscar uma colocação consagrada na nossa língua, que possa surtir efeito similar no público-alvo. No nosso caso, optamos por manter a imagem do céu, lançando mão de uma colocação em português, 'céu aberto', que apresenta 688.000 resultados $^{2}$ no Google e também é usada como nome próprio: Pousada Céu Aberto, Céu Aberto Arte e Consciência (escola de arte), Céu Aberto (espaço de saúde).

Outra colocação, Witches' Brew, não representou um problema de tradução por termos uma colocação com o mesmo sentido, Poção mágica ${ }^{3}$. Poção mágica tem 31.700 resultados, ${ }^{4}$ mas não devemos esquecer que o volume de material em inglês, disponível na web, é infinitamente maior do que o material em português, de modo que essa frequência é válida para nossos objetivos.

Outro título para o qual encontramos um equivalente em português foi Time out, termo que, entre outros sentidos, refere-se ao tempo de descanso num jogo, razão pela qual optamos por 'Meio tempo', mantendo o domínio do esporte.

Um caso bastante interessante foi o suco denominado Traffic light, que significa 'farol', 'semáforo' ou ainda 'sinaleira', dependendo da região do nosso país. O suco, de fato, emula um farol, pois tem três camadas: uma verde, uma amarela e uma vermelha. Nesse caso, para evitar algum regionalismo, optamos por ressignificar uma expressão relacionada ao trânsito: 'pare, olhe, siga'. Trazendo-a para o universo do livro, criamos Pare, olhe, beba, acreditando que o pequeno leitor fará a ligação desse título com um farol de trânsito.

Outro título que envolve um jogo de palavras é Raspberry crush, pois crush pode ser entendido como uma bebida (existia antigamente um

2 Acesso em: 20 jul. 2015.

3 Em inglês, existe magic brew, equivalente de 'poção mágica', mas com baixa frequência: 68.600 resultados, contra 483.000 para witches brew. Acesso em: 20 jul. 2015.

4 Acesso em: 20 jul. 2015. 
refrigerante de laranja chamado Crush) ou como o verbo 'to crush', que significa 'amassar, comprimir, quebrar'. Em linguagem informal, entretanto, 'crush' ocorre na expressão to have a crush on somebody, ou seja, 'ter uma queda por alguém'. Nesse sentido, podemos correlacionar crush com 'afeto'. Em português, o verbo 'amassar' dá origem ao substantivo 'amasso' que, como crush em inglês, denota alguma forma de 'afeto': 'dar um amasso em alguém'. Dessa forma, o título em português foi Amasso de framboesa.

O suco denominado Nutty Professor é o título de um filme com Eddie Murphy, conhecido em português como Professor Aloprado. Temos aqui novamente um jogo de palavras, já que nutty tem o sentido de 'relacionado a nozes' (nuts em inglês) e, em linguagem informal, significa 'maluco, louco', daí a tradução em português. Entretanto, se mantivéssemos como título do suco em português o nome do filme, perderíamos a referência aos ingredientes do suco, vários tipos de nozes. Daí, buscamos algum personagem que pudesse manter essa dupla leitura e lembramos de Minduim, nome de uma tira de jornal do cartunista americano Charles Schultz, cujo personagem principal é Charlie Brown. Optando por Minduim, mantivemos a ligação com o universo infantil e com os ingredientes do suco.

\subsection{Títulos que fazem referência ao universo infantil}

Esses envolvem, em geral, personagens, livros ou jogos do mundo infantil. Purple Tiger reflete a cor arroxeada do suco, que é feito com amoras e mirtilos, mas também faz referência a um personagem de histórias infantis bastante conhecido em nosso país, o Tigrão, em inglês Tigger. Face a isso, denominamos o suco simplesmente Tigrão.

O título Princess Peachy provém de uma personagem fictícia da série de videogames Super Mario Bros., produzida pela Nintendo. ${ }^{5}$ Salvo engano, essa personagem não é muito conhecida de nosso público infantil. Entretanto, há uma boneca com o nome de Pesseguinho que conjuga, como o título em inglês, o universo infantil e o ingrediente do suco, pêssego.

\footnotetext{
${ }^{5}$ Cf. $<$ https://pt.wikipedia.org/wiki/Princesa_Peach $>$.
} 
Dois títulos eram baseados em livros infantis, Black Beauty e Wakey-wakey. O primeiro é de autoria de Anne Sewell e foi traduzido para o português como Beleza Negra. Entretanto, uma busca no Google revelou que essa combinação era mais comumente associada à beleza da mulher negra. Dos 405.000 resultados, no Google, para "beleza negra", 291.000 coocorriam com mulher, enquanto apenas 93.900 tinham relação com o livro. ${ }^{6} \mathrm{~A}$ fim de evitar a leitura relacionada à beleza da mulher, optamos por Corcel Negro, que também é uma história sobre um cavalo, escrita por Walter Farley (em inglês Black Stallion), e que ensejou três filmes dirigidos por Carroll Ballard: The Black Stallion (1979), The Black Stallion Returns (2003) e The Young Black Stallion (2003), além da série de TV The Adventures of the Black Stallion, produzida entre 1990 e $1993 .^{7}$

O segundo livro, Wakey-wakey, de autoria de Dawn Apperlley, traz no título uma expressão empregada para acordar alguém. Como, em português, 'acorda, acorda' não é uma expressão consagrada, optamos por manter a repetição e usar uma expressão relacionada a regozijo e alegria, Oba-oba, com a intenção de incentivar a criança a tomar o suco.

Wacky Wizard é um jogo de tabuleiro em que os jogadores, para ganhar, têm de desfazer a magia do bruxo, mas também remete a shows de mágica. Ambas as referências seriam desconhecidas de nosso público. Porém, um personagem conhecido é o Mágico de $O z$, que mantém a relação com o mundo da magia e foi a opção final para o título desse suco.

Já Captain Zinger não apresentou problema, porque esse personagem é conhecido no Brasil como Capitão $Z$.

Em contrapartida, o suco Jungle Fever causou muita estranheza, pois essa é uma das denominações de 'malária' ou 'febre amarela' em inglês - referência que nos pareceu incompatível com o nome de um suco para crianças. Uma pesquisa na web revelou tratar-se também de um jogo de tabuleiro. Como o suco era amarelo - daí o título - buscamos algum jogo infantil que pudesse preservar essa referência e chegamos a

\footnotetext{
${ }^{6}$ Acesso em: 20 jul. 2015.

${ }^{7}$ Cf. $<$ https://pt.wikipedia.org/wiki/The_Black_Stallion>.
} 
Amarelinha, que recupera a cor da bebida, além de remeter ao universo dos jogos infantis.

\subsection{Título que reflete o efeito desejado}

Um dos sucos é denominado Easy Rider, nome de um filme de 1969, traduzido para o português como Sem Destino. O efeito pretendido pelo suco é o de aliviar enjoos em viagens, razão pela qual o título do filme em português seria claramente inadequado. Para manter o uso de uma categoria convencional, optamos por Boa viagem, uma fórmula comumente empregada quando alguém vai viajar.

\subsection{Título que envolve efeito prosódico}

Um dos sucos faz uso de aliteração: Frisky frog. É feito com kiwis e uvas verdes, o que lhe dá a coloração verde, motivando o 'sapo' (frog, em inglês) do título. Além disso, é um suco energético para que a criança logo esteja revigorada e "brincando por aí". Dessa forma, para manter o efeito prosódico, mantendo o animal, fizemos uso de rima, denominando o suco de Sapo no papo.

\subsection{Títulos com combinação de estratégias}

Run rabbit run é um título que envolve aliteração, é o nome de uma canção de 1939, é o nome de um livro infantil, além de ser o título de um romance de John Updike (obviamente para o público adulto). A referência pretende aludir à característica do suco, pois trata-se de "um excelente laxante natural" (CROSS, 2007b, p. 59). A tradução sugerida foi Corre-corre, por ser uma combinação consagrada em nossa língua e remete ao efeito desejado. ${ }^{8}$

\subsection{Traduções que exigiram adaptações culturais}

8 A editora alterou o título para Corre, coelhinho, corre. 
A tradução de alguns títulos demandou adaptações culturais mais específicas. Por exemplo, Kick Start remete à forma de dar partida numa motocicleta. Transpusemos essa ideia para o domínio do futebol, assunto com o qual o público infantil brasileiro está mais familiarizado, e traduzimos como Pontapé inicial.

Caso similar foi o suco Super Stripy que, literalmente, quer dizer 'super listrado'. Visualmente, apresenta três camadas: a inferior é um purê de mirtilos de coloração bastante escura, a do meio é de coalhada seca com mel, portanto branca, e a última é um purê de framboesa, ou seja, avermelhada. As cores lembram o sorvete tricolor chamado Napolitano (chocolate, creme e morango) e foi esse o título que the demos em português.

Finalmente, Little Pinky traz o nome do menor dedo da mão. Entretanto, 'mindinho' não faz qualquer alusão à cor do suco, cuja base é a polpa de melancia, de modo que tem uma cor avermelhada. $\mathrm{Na}$ tentativa de manter a referência à cor e incluir um pouco da cultura de nosso país, a tradução sugerida foi Boto rosa, personagem de uma lenda amazônica. ${ }^{9}$

\section{Considerações finais}

Nosso objetivo foi discutir a tradução do inglês para o português de alguns títulos de sucos do livro Juices \& Smoothies for Kids, de autoria de Amanda Cross. A maioria dos nomes envolve algum jogo de palavras ou manipulação criativa para tornar o suco atraente para o público infantil. Entre as estratégias empregadas, apontamos o uso de colocações em contexto não usual, recursos prosódicos como rimas e aliterações, referências ligadas ao universo infantil, como personagens, nomes de livros e jogos. Alguns nomes são motivados pela cor do suco ou pelo efeito desejado.

Nesse tipo de tradução, conforme já apontaram vários autores, assim como os adeptos da teoria funcionalista da tradução, o importante

9 A editora substitui-o por Mix refrescante. 
é priorizar o 'efeito' pretendido no público-alvo, em detrimento da 'forma'. Para tanto, é primordial reconhecer a estratégia utilizada para nomear o suco e tentar reproduzi-la na língua de chegada. Quando isso não é possível, cabe ao tradutor criar um novo título que mantenha o efeito apelativo pretendido. $\mathrm{Na}$ maioria dos casos relatados, isso foi obtido; em outros, fizeram-se necessárias adaptações culturais. No geral, acreditamos ter alcançado o objetivo de produzir títulos apelativos ao público infantil.

\section{Referências}

ASIMAKOULAS, D. Towards a Model of Describing Humour Translation. A Case Study of the Greek Subtitled Versions of Airplane! and naked Gun. Meta , 49, p. 822-842, 2004.

ATTARDO, S. Translation and Humor: an Approach Based on the General Theory of Verbal Humor (GTVH). The translator. Editor: J. Vandaele, v. 8, p. 173-194, 2002.

BREZOLIN, A. Humor: sim, é possível traduzi-lo e ensinar a traduzi-lo. TradTerm - Revista do Centro Interdepartamental de Tradução e Terminologia, 1, p. 15-30, 1997.

BRUNET, C. D. A tradução do humor sob a perspectiva da Teoria da Relevância. Monografia (Especialização) - Universidade Tuiuti do Paraná, Curitiba, 2014

CROSS, A. Juices and Smoothies for Kids. London: Hamlyn, 2007a.

CROSS, A. Sucos e Vitaminas para Crianças. Trad. S. E. Tagnin. Barueri, SP: Manole, 2007b.

CUNHA, A. M. A tradução da comicidade linguística em Alice's Adventures in Wonderland. Monografia (Graduação em Letras) Universidade Federal de Juiz de Fora, 2004.

DELABASTITA, D. Wordplay and Translation. Manchester: St. Jerome Publishing, 1996. 
DELABASTITA, D. Traductio - essays on punning and translation. 2. ed. V. 2. Langues et littératures. Manchester: St. Jerome Publishing and Presses Universitaires de Namur, 1997. 296 p.

FILLMORE, C. J. Innocence. A second idealization for linguistics. In: ANNUAL MEETING OF THE BERKELEY LINGUISTICS SOCIETY, 5, 1979, Berkeley. Proceedings... Ed.: C. Chiarello. Berkeley, CA: Linguistics Society, 1979. p. 63-76.

NIEDZIELSKI, H. Cultural Transfers in the Translation of Humor. In: LARSON, M. (Ed.). Translation: Theory and Practice - Tension and Interdependence. Binghampton, NY: State University of New York, 1991. p. 139-156.

PHILIP, G. Arriving at equivalence. Making a case for comparable corpora in Translation Studies. In: BEEBY, A.; RODRIGUEZ INÉS, P.; SÁNCHEZ-GIJÓN, P. Corpus Use and Translating: Corpus Use for Learning to Translate and Learning Corpus Use to Translate. Amsterdam: John Benjamins, 2009.

REISS, K.; VERMEER, H. J. Fundamentos para um teoría funcional de la traducción. Trad.: S. Reina; C. de León. Madrid: Akal, 1996.

ROSAS, M. Tradução de Humor - Transcriando Piadas. Rio de Janeiro: Lucerna, 2002.

SCHÄFFNER, C. Functionalist approaches. In: BAKER, M.; SALDANHA, G. Routledge Encyclopedia of Translation Studies. New York: Routledge, 2009. p. 115-121.

SCHMITZ, J. R. Humor: é possível traduzi-lo e ensinar a traduzi-lo? TradTerm: Revista do Centro Interdepartamental de Tradução e Terminologia, 3, p. 87-97, 1996.

SILVA, N. R. A tradução de jogos de palavras no romance $O$ xangô de Baker Street: uma revisão do quadro de estratégias de Delabastita com o auxílio da Linguística de Corpus. Tese (Doutorado em Linguística) FFLCH - Universidade de São Paulo, São Paulo: 2015. 
SILVA, N. R. Um Estudo sobre a Recepção do Humor Traduzido. Dissertação (Mestrado em Letras) - Universidade Estadual do Ceará, Fortaleza, CE, 2006.

STEWART, D. Conventionality, Creativity and Translated Text: The Implications of Electronic Corpora in Translation. In: OLOHAN, M. Intercultural Faultlines. Manchester, Northampton: St. Jerome Publishing, 2000. p. 73-91.

TAGNIN, S. E. O humor como quebra da convencionalidade. Revista Brasileira de Linguística Aplicada, 5, n. 1, p. 247-257, 2005.

TAGNIN, S. E. O jeito que a gente diz: combinações consagradas em inglês e português. São Paulo: Disal, 2013.

ZABALBEASCOA, P. Translating Jokes for Dubbed Television Situation Comedies. The translator , 2, p. 235-257, 1996. 